\title{
REMUNERAÇÃO ESTRATÉGICA- ESTUDO DE CASO EM UMA EMPRESA DO COMÉRCIO VAREJISTA DE MATERIAIS PARA CONSTRUÇÃO EM TANGARÁ DA SERRA-MT
}

\author{
Andressa Ozan Oliveira ${ }^{1}$ \\ Julio Cezar de Lara ${ }^{2}$
}

\section{RESUMO}

Remuneração estratégica é um conjunto de inúmeras formas de recompensas aos colaboradores. Representa vantagem competitiva e uma ferramenta diferenciada para as organizações, pois inserida de forma adequada valoriza seus colaboradores e os tornam mais motivados. Considerando este contexto, em janeiro de 2012, foi realizado este estudo em uma empresa do comércio varejista de materiais para construção instalada na Cidade de Tangará da Serra, com aplicação de questionários de forma censitária aos colaboradores. Questionouse a existência de diversas formas de remuneração estratégica e qual seria a mais usual aplicada. Como hipótese ao questionamento, idealizamos que a empresa não adotava vários tipos de remuneração, e, caso adotasse, a forma mais usual seria a remuneração variável. Assim o objetivo geral do estudo foi identificar qual a estratégia de remuneração mais usual na empresa. Para a realização deste estudo adotou-se a metodologia, quanto aos fins, de caráter descritivo e explicativo com utilização da técnica de estudo de caso, e quanto aos meios, utilizou-se da pesquisa bibliográfica, que proporcionou a possibilidade de fundamentar-se em livros e pesquisas telematizadas. $O$ resultado observado foi que, ao contrário do que se pensava, a empresa adota vários tipos de remuneração estratégica, e a forma mais usual de remunerar os colaboradores é a remuneração funcional, ou seja, uma remuneração determinada pelo cargo/função e ajustada ao mercado.

Palavras chave: Sistemas de remuneração. Motivação. Recompensas.

\section{INTRODUÇÃO}

Entende-se por atividade comercial a troca de mercadorias por dinheiro ou de uma mercadoria por outra. Para Iudícibus e Marion (2004) a atividade comercial é essencial a natureza das necessidades humanas, pois todos nós temos necessidades e caso não existisse a moeda, trocaríamos nossos bens em excessos por outros que não temos, ou seja, a comercialização de produtos é umas das mais importantes atividades, pois coloca a disposição dos consumidores, grande variedade de bens e serviços, que são necessários a satisfação dos seres humanos.

Atualmente vem ocorrendo constantes mudanças, tanto nos aspectos legais, econômicos, organizacionais e sociais, e a atividade de comercialização deve acompanhar o ritmo e mudar na mesma velocidade para se adaptar e sobreviver. As organizações, por sua

\footnotetext{
1 Acadêmica do curso de Ciências Contábeis da UNEMAT - Campus de Tangará da Serra, e-mail: andressaozan@gmail.com

${ }^{2}$ Professor Especialista em Administração Pública do curso de Administração da UNEMAT - Campus de Tangará da Serra, e-mail: juliocezar.lara@gmail.com 
Remuneração estratégica- estudo de caso em uma empresa do comércio varejista de materiais para construção em Tangará da Serra-MT

Andressa Ozan Oliveira

Julio Cezar de Lara

$\overline{\text { vez, devem se adequar e acompanhar toda essa evolução, para que possam se sobressair neste }}$ cenário de competitividade que ocorre.

Veloso et al (2008) afirmam que as organizações atuais devem se tornar flexíveis, estabelecendo estratégias de desenvolvimento, realizando freqüentes atualizações tecnológicas e, sem dúvidas, valorizando seu capital humano, capacitando seus colaboradores, motivando e desenvolvendo seu crescimento pessoal.

Percebe-se que é indispensável às organizações a formulação de um plano que envolva a satisfação do público interno. Uma das formas de chegar à satisfação desse público é através da remuneração paga. Uma remuneração adequada e bem estruturada, não só criará um diferencial no atendimento e na qualidade dos seus produtos e serviços, mas também valorizará os colaboradores para que a organização possa atingir seus objetivos.

Uma maneira de se remunerar atualmente é através da remuneração estratégica, que se apresenta como um modelo de compensação que premiam os colaboradores da empresa, que por alguma razão, se destacaram dos demais em certo período. Marras (2002) afirma que a remuneração estratégica faz com que os colaboradores passem a ser considerados em conformidade com inúmeros fatores que possuem, e influenciam diretamente nos resultados oferecidos a entidade. As bases que sustentam o modelo de remuneração estratégica são formadas por um conjunto de três fatores essenciais: conhecimentos, habilidades e atitudes.

Desta forma cada empresa pode possuir um sistema de remuneração estratégica formulado de acordo com suas necessidades, pois segundo Chiavenato (1992) a remuneração estratégica engloba: atrair e manter o pessoal altamente qualificado, recompensar os serviços prestados de forma a reconhecer o desempenho passado, motivar o desempenho futuro, assegurar a equidade num ponto de vista interno e externo e atender as normas legais.

Diante da importância do tema, o problema proposto foi verificar qual é a forma de remuneração mais utilizada em uma empresa comercial do ramo varejista de materiais para construção em Tangará da Serra-MT? Tendo como objetivo geral identificar a estratégia de remuneração é a mais utilizada em uma empresa comercial de materiais para construção de Tangará da Serra - MT,e tendo como objetivos específicos, identificar na literatura quais são os tipos de remuneração utilizados pelas organizações e empresas comerciais; analisar in loco os tipos de remuneração existentes; verificar a existência ou aplicação de qualquer tipo de remuneração estratégica na empresa e, por fim; verificar se os colaboradores estão satisfeitos com a atual remuneração obtida. 
Remuneração estratégica- estudo de caso em uma empresa do comércio varejista de materiais para construção em Tangará da Serra-MT

Andressa Ozan Oliveira

Julio Cezar de Lara

As hipóteses levantadas para realização da pesquisa foram: a) A empresa não adota vários tipos de remuneração em seu ambiente organizacional b) A remuneração variável é a forma mais usual de remuneração estratégica utilizada na empresa.

A presente pesquisa se justifica por abordar um tema interessante no âmbito de identificar a forma de atuação de remuneração da empresa, já que o processo de remunerar pessoas é um dos fatores de grande relevância para a motivação e desempenho dos colaboradores e para um bom desenvolvimento das empresas.

Esta pesquisa também se torna relevante, pois aponta como os colaboradores se sentem na questão de satisfação com relação a remuneração recebida, e se o sistema de remuneração utilizado satisfaz as necessidades da empresa, sendo este um dado importante para os gestores, colaboradores e empresários, haja vista que atualmente a maneira utilizada para manter, reter e motivar colaboradores são fatores de extrema relevância que devem estar sempre a frente em uma organização, e atrelada com o sistema de remuneração adequado atendem as necessidades especificas de cada empresa.

Por fim, a pesquisa trás uma grande contribuição para a sociedade, acadêmicos, e professores, pois servirá de base para novas pesquisas, para um melhor entendimento de como uma empresa do comércio varejista remunera seus colaboradores, e como os mesmos se sentem em trabalhar na empresa, tanto em âmbitos de satisfação, motivação e desempenho. Sendo também de grande contribuição para a empresa onde foi realizada a pesquisa, pois obtivemos resultados concretos sobre os aspectos humanos.

\section{REFERENCIAL TEÓRICO}

\subsection{Administração de recursos humanos}

A área de Administração de Recursos Humanos (ARH) é um setor que envolve entre muitos conceitos de administração, conceitos de psicologia e sociologia organizacional. Ela visa o planejamento da organização para que haja um desempenho do seu pessoal. A ARH mantém as pessoas na organização para que trabalhem e dêem o máximo de si, visando a qualidade de vida e a definição do perfil de cada colaborador que a empresa deseja cultivar. É uma área que trata do recrutamento, seleção, treinamento, desenvolvimento, manutenção, controle e avaliação de pessoas (VELOSO et al, 2008). 
Remuneração estratégica- estudo de caso em uma empresa do comércio varejista de materiais para construção em Tangará da Serra-MT

Andressa Ozan Oliveira

Julio Cezar de Lara

A expressão "Gestão de Pessoas" vem substituindo a chamada "Administração de

Recursos Humanos" e hoje já está entre as expressões mais comuns utilizadas atualmente para mencionar os modos de lidar com as pessoas dentro das organizações (GIL, 2001).

Os seis processos básicos de gestão de pessoas são: processo de agregar pessoas, de aplicar pessoas, de recompensar pessoas, de desenvolver pessoas, de manter pessoas e processo de monitorar pessoas.

De acordo com Chiavenato (2008) o processo de recompensar pessoas, assunto foco da presente pesquisa, constitui elementos fundamentais para incentivar e motivar os colaboradores da organização. Veremos que de um lado existem os objetivos organizacionais a serem alcançados, e de outro lado, os objetivos individuais a serem satisfeitos. A recompensa é um componente fundamental para a condução das pessoas em termos de retribuição, retroação ou reconhecimento do seu desempenho na organização.

\subsection{Remuneração}

Atualmente as pessoas procuram ingressar em empresas que valorizem seu desempenho e que reconheçam seus esforços. As pessoas comparam as empresas para ver quais são as mais atraentes financeiramente e quais possuem maiores benefícios. Os tipos de remuneração existentes dentro da organização é o que faz o diferencial na realização das tarefas executadas pelos colaboradores.

Segundo Dutra (2006) apud Malanovicz, Weber (2010) pode-se entender o termo "remuneração" como a forma de valorização das pessoas pela empresa, e essas recompensas devem atender expectativas e necessidades pessoais, como: econômicas, crescimento pessoal e profissional, segurança, projeção pessoal, reconhecimento, possibilidade de se expressar em seu trabalho, dentre outros.

Mais do que o poder de compra ou o padrão de vida que os salários e outras formas de recompensas proporcionam, sua importância está atrelada a um valor simbólico, onde representa o valor que o funcionário tem para a organização. Por isso as práticas de recompensas devem estar próximas daquilo que a organização valoriza e quer estimular em seus profissionais, incentivando comportamentos e ações que agreguem valor, desta forma gerando equilíbrio entre a estrutura compensatória e resultados obtidos pela organização (HIPOLITO, 2002, apud MALANOVICZ, WEBER, 2010).

Remuneração é a soma de tudo o que pago periodicamente aos colaboradores em função de seus serviços prestados: salários, gratificações, adicionais, assim como todos os 
Remuneração estratégica- estudo de caso em uma empresa do comércio varejista de materiais para construção em Tangará da Serra-MT

Andressa Ozan Oliveira

Julio Cezar de Lara

benefícios financeiros, como prêmios por produtividade, participações nos resultados e opção de compra de ações, dentre outros (LIMA; NEU; CACENOTE, 2010).

\subsection{Remuneração estratégica}

Remuneração estratégica é um conjunto de inúmeras maneiras para remunerar os colaboradores, é uma ligação entre o indivíduo e a nova realidade das organizações, sendo esta ligação de duas maneiras: primeira, no sentido de considerar todo o sentido organizacional como a estratégia, estrutura e o estilo organizacional, e segunda, à medida que os indivíduos passam a ser remunerados de acordo com a sua contribuição para a empresa (GIL, 2001).

A remuneração estratégica deve considerar todo o contexto onde está inserida a organização, e levar em conta suas características e projetos atuais e futuros. É uma forma de ocorrer um maior vínculo entre os colaboradores e a empresa (RODRIGUES et al, 2008).

Logo, pode-se definir remuneração estratégica como sendo uma junção de todas as ferramentas que possuídas atualmente englobam a remuneração funcional, salários indiretos, remuneração por habilidades e competências, remuneração variável, participações acionárias e dentre outras formas de se remunerar. Assim, busca-se poder remunerar de forma altamente competitiva, fazendo com que o profissional procure estar altamente qualificado na execução de suas atividades, pois quanto maior o seu grau de conhecimento, maior poderá ser a sua remuneração, e desta forma a organização terá um diferencial nos âmbitos de qualificação, motivação e atendimento, e se sobressairá com relação à concorrência.

\subsubsection{Sistemas de remuneração estratégica}

A criação de um sistema de remuneração estratégica considera não apenas o que a empresa é hoje, mas o que ela espera ser no dia de amanhã. Sendo assim, é necessário que se visualize todo o contexto organizacional, levando em conta a estratégica, a estrutura e o estilo gerencial. Por outro lado os profissionais passam a ser remunerados de acordo com o conjunto de fatores que afetam sua contribuição para o sucesso do empreendimento: características pessoais, do cargo e vínculos com a organização, e também as atividades e responsabilidades, assim como, conhecimentos, habilidades, competência, desempenho, resultados e evolução de carreira (NASCIMENTO, 2001). 


\section{Remuneração estratégica- estudo de caso em uma empresa do comércio varejista de materiais para construção em Tangará da Serra-MT \\ Andressa Ozan Oliveira \\ Julio Cezar de Lara}

Todo o sistema de remuneração estratégica exige um perfil diferenciado de organização. Dificilmente um modelo remuneratório desse gênero poderá ser implementado em uma organização onde impere a hierarquia rígida, com modelos de tomada de decisão centralizados e onde não é privilegiada a autonomia de ações, a criatividade e o sentido de equipe. Pelo contrário, o ambiente organizacional que aguarda um sistema de remuneração estratégico é bem mais desenhado para uma gestão de empresa inovadora, onde exista um investimento real sobre as potencialidades do ser humano, e onde a partir do acionista, haja um convencimento de que o homem é realmente o fator diferenciador na expectativa de atingir os objetivos maiores da empresa (MARRAS, 2002).

Ainda segundo Marras (2002, p.172):

O sistema estratégico de remuneração, de qualquer maneira, em qualquer circunstancia, pode ser avaliado como um mecanismo que, paralelo ou não ao modelo de remuneração fixa ou tradicional, é uma certa forma de avanço, de movimento, de desenvolvimento de médio e longo prazos em que os trabalhadores recebem um plus na exata medida de sua contribuição para o sucesso do negocio e, quando implantado no ambiente adequado, de forma adequada, representa realmente um instrumento gerencial do mais alto grau.

O sistema de remuneração desenvolvido de forma cuidadosa para a empresa constituise em vantagem competitiva. As comparações com o mercado perdem um pouco de sua importância, porém, não pode haver um desvinculamento com ele. É necessário que se viabilize as formas de comparação, para evitar que as empresas fiquem completamente alheias ao que acontece no mercado. A construção do sistema de remuneração estratégica deve ter a participação de representantes dos vários grupos de poder, que definirão os principais pontos que deverão estar alinhados com os objetivos estratégicos da empresa e com foco no comportamento necessário para seu atendimento. Os principais pontos são: melhoria do desempenho, valor da recompensa, reconhecimento, estabelecimento de metas, desenvolvimento, atração e retenção (NASCIMENTO, 2001).

Desta forma, ao adotar um sistema de remuneração estratégica, a organização deve proceder um diagnóstico da real situação da empresa no mercado atual, e direcionar sua missão, para que adquira os sistemas de remuneração que vão de encontro a sua realidade e garanta uma continuidade desse sistema.

Segundo o estudo realizado por Vilas Boas, Batista (2004) em empresas brasileiras, foram levantados os dados de que as empresas que possuem a metodologia de remuneração por habilidades e/ou competências apresentam um aumento na motivação e do incentivo ao desenvolvimento profissional. As que possuem metodologia de remuneração funcional 
Remuneração estratégica- estudo de caso em uma empresa do comércio varejista de materiais para construção em Tangará da Serra-MT

Andressa Ozan Oliveira

Julio Cezar de Lara

apresentaram algumas situações de acomodação e injustiça por parte dos colaboradores e em outras situações apresentaram bons resultados, devendo, portanto ser administrada com cautela. E as que possuem metodologia de remuneração por participação nos lucros e resultados, apresentaram um aumento de produtividade, da qualidade e lucratividade empresarial.

\subsection{Formas de Remuneração}

Serão apresentados os vários tipos de remuneração estratégica existente dentro das formas de remuneração.

\subsubsection{Remuneração funcional}

A prática de tornar o cargo como base para a fixação do salário do trabalhador, assim como todos os seus rendimentos decorrentes do trabalho, é chamado de remuneração funcional (CARDOSO, 2006).

De acordo com Wood Jr e Picarelli Filho (2004) a remuneração Funcional ou tradicional, é determinada pela função (cargo) e ajustada ao mercado. Este tipo de remuneração é o mais tradicional que existe, é chamado de Plano de Cargos e Salários, também conhecido pela sigla PCS. Ela se mantém ainda como o modelo mais popular em uso. Grandes empresas que utilizam este tipo de remuneração tendem ao conservadorismo e à inércia.

O PCS considera alternativas que permitem ao gestor administrar recursos humanos de forma estimulante e competitiva, normatizando relações de trabalho, valorizando o conhecimento, a competência e o desempenho da força de trabalho (SOCHODOLAK, MELO JUNIOR, 2008).

Um plano de cargos e salários, que é o modelo mais tradicional de remuneração, tem normalmente como objetivo a equidade interna e externa, o controle financeiro dos gastos de remuneração, o controle de promoções e o cumprimento da legislação. Para atender os objetivos estratégicos, o PCS tem sido conectado a um sistema de recompensas mais flexível (FERRÃO, 1999).

\subsubsection{Salários Indiretos}

Segundo Chiavenato (2005 p. 292) os salários indiretos são “Os benefícios e serviços aos colaboradores que visam satisfazer vários objetivos econômicos, sociais e individuais". 
Remuneração estratégica- estudo de caso em uma empresa do comércio varejista de materiais para construção em Tangará da Serra-MT

Andressa Ozan Oliveira

Julio Cezar de Lara

O salário indireto compreende essencialmente os benefícios oferecidos pela empresa aos seus colaboradores. Esses benefícios respondem por uma parte considerável da remuneração total e normalmente é um fator decisivo no aceite de oferta de empregos. Os benefícios têm impacto direto sobre a qualidade de vida dos colaboradores, e isso influencia na sua segurança atual e futura e também na sua condição de vida (WOOD JR, PICARELLI FILHO, 1999, apud ESTIVALETE; NAKAYAMA, BINOTTO, 2009).

Desta forma entende-se que os salários indiretos são incentivos e benefícios proporcionados aos colaboradores, sendo eles: férias, gratificações, gorjetas, adicionais (de periculosidade, insalubridade, noturno, tempo de serviço), horas extraordinárias, alimentação subsidiada, transporte subsidiado, seguro de vida em grupo, entre outros (FERRÃO, 1999).

\subsubsection{Remuneração por habilidade}

É constituída por um sistema que recompensa avanços no setor cognitivo dos trabalhadores, onde avalia o desenvolvimento de conhecimentos que eles adquirem e das respectivas habilidades ou bloco de habilidades previamente fixadas como metas em cada etapa do sistema (MARRAS, 2002).

Segundo Chiavenato (2005) existem dois modos de remunerar o colaborador por sua habilidade: pelo conhecimento e pela multi-habilidades. A análise do conhecimento do funcionário segue uma idéia de adquirir formação, cursos e treinamentos que ajudam a difundir o conhecimento do cargo exercido na empresa. As multi-habilidades provêm de mudança de comportamento por parte dos grupos de trabalho. Isto ajuda a mensurar a qualidade e evolução do trabalho realizado. Nesse tipo de remuneração o colaborador precisa de um número maior de treinamento, já que ele irá desempenhar várias tarefas durante o seu serviço.

A operacionalização da remuneração por habilidade exige que sejam definidos quais habilidades ou blocos de habilidades devem ser desenvolvidas, para que se estabeleçam passos para a evolução dos colaboradores, além de processos e regras para treinamento e comprovação (NASCIMENTO, 2001).

Ainda segundo Nascimento (2001, p.134):

Num sistema de remuneração por habilidade, os funcionários trabalham em equipes autogerenciadas, desempenhando várias funções. A célula básica da remuneração passa a ser a habilidade ou o conjunto de habilidades. A habilidade é entendida como a aptidão ou competência para realizar algo. Remuneração por habilidade individual ocorre quando esta tem alta complexidade. Remuneração por conjunto de 


\section{Remuneração estratégica- estudo de caso em uma empresa do comércio varejista de materiais para construção em Tangará da Serra-MT \\ Andressa Ozan Oliveira \\ Julio Cezar de Lara}

habilidades, quando é possível constituir grupos de habilidades simples. Trabalhar com conjunto de habilidades simplifica a administração do sistema.

Sendo assim a remuneração por habilidades tem o objetivo de valorizar as pessoas da organização pelo uso de suas capacidades e um conseqüente aperfeiçoamento delas, promovendo uma diferença quanto à concorrência no mercado globalizado onde se busca a qualidade e a motivação dos colaboradores.

\subsubsection{Remuneração por competência}

Este tipo de remuneração se aplica mais adequadamente ao nível de funcionários em papéis de liderança, controle, planejamento, responsabilidade de resultados, e administradores no sentido amplo. Definir competência é o primeiro passo que se deve realizar ao pensar na possibilidade de implementar um sistema de remuneração a que se refere. Assim surge o primeiro obstáculo: definir de forma eficaz o que se entende por competência sem entrar no campo das características pessoais dos indivíduos e das habilidades (MARRAS, 2002).

A Remuneração por Competência supera algumas restrições da Remuneração por Habilidades, o aspecto principal é adotar esse sistema de uma forma criativa que possa contribuir para estratégia da empresa, já que este sistema de remuneração analisa a criatividade e a personalidade do colaborador, sendo utilizada primeiramente para o corpo executivo ou gerencial da empresa e em seguida para todos os trabalhadores (WOOD JR, PICARELLI FILHO, 2004).

Para que haja sucesso na execução de um programa de remuneração, deve se levantar quais as habilidades e competências são essenciais a organização. Isso deve ser feito em grupos e de forma individual, para obter resultados positivos e para se remunerar de forma adequada, promovendo assim a motivação e o alcance de metas.

\subsubsection{Remuneração Variável}

A remuneração flexível ou variável é uma forma de adequar o pacote às necessidades individuais de cada pessoa.

Os planos de tipo menu oferecem à pessoa um pacote total de remuneração direta e indireta em que ela deve escolher como alocar ou gastar o seu dinheiro. Pode receber tudo em dinheiro ou parte em benefícios sociais. Em alguns planos, a escolha ocorre somente dentro da categoria de benefícios. Esse tipo de sistema é desenhado para 


\section{Remuneração estratégica- estudo de caso em uma empresa do comércio varejista de materiais para construção em Tangará da Serra-MT \\ Andressa Ozan Oliveira \\ Julio Cezar de Lara}

assegurar que a pessoa esteja trabalhando para receber recompensas que ela realmente quer receber (CHIAVENATO, 2005, p. 299).

A remuneração variável é atrelada a metas de desempenho dos indivíduos, das equipes ou da organização. Ela inclui formas de remuneração de curto prazo, como as comissões e participação nos lucros e resultados, e de longo prazo como bônus executivo (WOOD JR, PICARELLI FILHO, 2004).

Para obter sucesso, a prática da remuneração variável nas empresas deve contemplar o indivíduo, o grupo, o setor, e a empresa como um todo, além de contemplar o consumidor com produtos e/ou serviços de melhor qualidade, dentre outros fatores. A Remuneração variável pode servir de base para a parceria global, estimulando a aproximação entre os componentes de uma equipe e proporcionando um crescimento profissional mais intenso. Essa parceria global agindo com a remuneração variável conduz a uma significativa sinergia entre indivíduos, equipes e empresa. Pelo fato de ser evitado o esforço isolado de um desempenho altamente significativo de um funcionário, cuja Remuneração variável em que pese ser maior que a de seus colegas de equipe, será menor que aquela que iria conseguir se todos tivessem os mesmos resultados ou se atingissem resultados mais próximos ao dele (NASCIMENTO, 2001).

De acordo com o resultado do estudo feito por Oliveira (2001), para identificar a forma de remuneração mais utilizada nas empresas, mostrou que a remuneração variável está sendo utilizada cada vez mais como forma de manter os recursos humanos com qualidade e incentivo no trabalho. Essa é uma mudança que vem ocorrendo nesta área e ficou evidenciado que $81,1 \%$ das empresas no Brasil utilizam alguma forma de remuneração variável, e que o tipo mais utilizado é a participação nos lucros.

A participação nos lucros trata de um sistema que permite contemplar com uma parcela em espécie a todos os colaboradores da empresa, em função dos dados da lucratividade que a empresa levanta no final de determinado período. Se a empresa obteve lucro em certo período, uma parte desse lucro é distribuída aos colaboradores equitativamente. Mas esse modelo de remuneração recebe muitas críticas, principalmente por parte dos trabalhadores e seus respectivos sindicatos, pois o resultado final não depende somente do esforço dos trabalhadores em produzir, mas também resulta da gestão global da empresa e de possíveis manipulações contábeis (MARRAS, 2002).

Segundo Lacombe (2005), na participação nos lucros, o ponto de partida é determinar o que se entende por lucro. É preciso também decidir o percentual sobre o lucro a ser 
Remuneração estratégica- estudo de caso em uma empresa do comércio varejista de materiais para construção em Tangará da Serra-MT

Andressa Ozan Oliveira

Julio Cezar de Lara

distribuído aos empregados, a cada nível hierárquico e as metas a serem alcançadas pelos grupos e pessoas. Os quais devem alcançar resultados contratados com a empresa para fazer jus a valores maiores de remuneração. $\mathrm{O}$ desempenho passa a ser um elemento importante na remuneração que não fica atrelada exclusivamente ao cargo. A remuneração passa a ser variável, com todas as vantagens e desvantagens daí advindas.

\subsubsection{Participação acionária}

A Participação Acionária é considerada uma remuneração de longo prazo, pois oferece para o colaborador uma co-participação da empresa, desta forma abrangendo uma relação de compromisso do funcionário com a organização (WOOD JR, PICARELLI FILHO, 2004).

O modelo de remuneração acionária aplica-se normalmente aos níveis estratégicos da organização e consiste em remunerar resultados conseguidos mediante concessão de ações da empresa, e torna esses executivos sócios do negócio, muito mais comprometido e com possibilidades de obter lucros com o jogo dessas ações. Conforme o funcionário vai acumulando ações da companhia, torna-se cada vez mais próximo da figura de proprietário, sua ótica e sua lógica de pensar e agir voltam-se completamente para este rumo, que é a visão de co-proprietário (MARRAS, 2002).

Existem basicamente duas formas de participação acionária segundo Marras (2002): distribuindo ações, em que a empresa separa um porcentual de ações que irá oferecer anualmente aos seus colaboradores, executivos ou não, de acordo com os resultados obtidos, e também vendendo ações, para aqueles colaboradores que tiverem interesse em adquirir ações da própria companhia em geral como fator de investimento. Nesse caso a companhia pode proporcionar formas de pagamento especiais para permitir essas aquisições.

De acordo com Marras (2000, apud Lima, Neu, Cacenote, 2010) a participação acionária é o modelo de remuneração mais comumente aplicado aos níveis estratégicos da organização, pois ela remunera o colaborador pelos resultados obtidos, concedendo ações a ele, ou seja, ele se torna mais comprometido pois se torna sócio do negócio, e se a empresa obtém lucro ele sai ganhando, mas se ela tiver prejuízo ele sairá perdendo, por isso causa um comprometimento maior com a organização.

\subsection{Motivação}


Remuneração estratégica- estudo de caso em uma empresa do comércio varejista de materiais para construção em Tangará da Serra-MT

Andressa Ozan Oliveira

Julio Cezar de Lara

Quanto mais se aprofunda o estudo do comportamento motivacional humano, mais claramente se percebe que a motivação de cada um está ligada a um aspecto que lhe é muito caro, aquele que diz respeito à sua própria felicidade pessoal (BERGAMINI, 1997 apud VELOSO et al, 2008).

Motivar pessoas não constitui tarefa fácil, uma vez que necessidades diferentes demandam formas diferentes de recompensa, e que cada indivíduo já traz consigo quando ingressa na organização um conjunto de fatores motivacionais intrínsecos estreitamente relacionados com habilidades e talentos pessoais. Os fatores motivacionais além de variarem de indivíduo para indivíduo, também variam ao longo de sua vida e em consequiência do ambiente no qual esteja inserido. É necessário que se descubra de que forma as recompensas constituem fator motivador para o colaborador, para que as tarefas não lhes pareçam tão somente imposições, mas que tenham um significado para sua execução. A motivação dos colaboradores passa a ser uma tarefa mais abrangente do que apenas recompensar financeiramente. Ela se torna uma busca diuturna e incessante da satisfação e realização através do trabalho (VELOSO et al, 2008).

Ao se falar de motivação, sempre surge a dúvida dos gestores de como se proceder para motivar os colaboradores. Esse fato é um grande equívoco cometido ao se estudar sobre motivação. Segundo Casado (2002) apud Dantas (2005) a motivação evidencia um impulso ou necessidade, se tornando um sentimento, algo que pode receber estímulos do meio, mas que é concebido internamente. Dessa forma esse questionamento dos gestores é algo impossível de ser realizado, pois não é possível que um agente externo promova motivação.

Sendo assim, podemos perceber que não existe sucesso em uma empresa onde não exista a motivação de seus colaboradores. A motivação é algo imprescindível para que os trabalhadores executem suas tarefas da melhor forma possível e obtenha bons resultados para si e para a organização, e se torna melhor ainda quando isso provem da utilização de bons sistemas de remuneração.

Onde se aborda a motivação, normalmente está inserida a valorização do capital intelectual, que vem sendo muito praticado nas empresas. A valorização de capital intelectual é o reconhecimento de que as pessoas têm necessidades intrínsecas e específicas, que o gestor deve utilizar da melhor maneira possível ao desenvolver o planejamento estratégico da organização e na operacionalização das atividades da empresa, desta forma aumentando sua produtividade e a tornando mais competitiva. Esta valorização ocorre através de recompensas que aumentam as expectativas e necessidades de seus colaboradores, e como essas 
Remuneração estratégica- estudo de caso em uma empresa do comércio varejista de materiais para construção em Tangará da Serra-MT

Andressa Ozan Oliveira

Julio Cezar de Lara

necessidades variam de pessoa para pessoa, deve ser distribuída de forma diferenciada a cada colaborador (RAMOS; FERREIRA, 2010).

Segundo uma pesquisa realizada por Gonsalez et al (2007), para verificar o principal fator motivacional dos colaboradores de uma empresa, constatou-se a remuneração (salários e benefícios) como sendo o principal fator, sendo um percentual de $85 \%$. Também constatou-se que equipes motivadas representam um aumento de lucros para as empresas, e que o reconhecimento do colaborador também representa um importante fator motivacional, tanto na opinião dos gestores quanto dos colaboradores.

\section{METODOLOGIA}

Neste trabalho o objeto de pesquisa foi uma empresa do ramo do comércio varejista de materiais para construção na cidade de Tangará da Serra, Mato Grosso, sendo uma pesquisa censitária e caracterizou o método de pesquisa como estudo de caso único.

Quanto aos fins metodológicos adotados para a realização desta pesquisa, foram considerados de caráter descritivo e explicativo. A caracterização da pesquisa como descritiva se fundamenta nas definições de Vergara (2009) onde relata que a pesquisa descritiva expõe características de determinada população ou determinado fenômeno, e explicativa, pois identifica os fatores que determinam ou contribuem para a ocorrência dos fenômenos.

Quanto aos meios metodológicos, foi utilizado o bibliográfico que é um apanhado geral sobre trabalhos já realizados e revestidos de importância e o estudo de campo que de acordo com Vergara (2009) é uma investigação empírica realizada no local onde ocorre ou ocorreu um fenômeno ou que dispõe de elementos para explicá-lo, podendo ainda incluir entrevista, aplicações de questionários, testes e observação participante ou não.

A técnica de estudo de caso também foi aplicada na realização deste trabalho, pois de acordo com Yin (2001) essa técnica pode envolver o estudo tanto em um único caso quanto em situações de múltiplos casos. O intuito da presente pesquisa foi realizar o estudo de caso de forma individual, para ter uma análise com maior profundidade e uma melhor compreensão dos dados obtidos.

Com relação à abordagem do problema foi de caráter qualitativo que visa à compreensão dos dados e o alcance dos objetivos, pois é uma pesquisa de ordem descritiva e não numérica. 
Remuneração estratégica- estudo de caso em uma empresa do comércio varejista de materiais para construção em Tangará da Serra-MT

Andressa Ozan Oliveira

Julio Cezar de Lara

Em um primeiro momento, foi realizado um estudo sistematizado com fundamentação teórica baseada em livros relacionados à área, e pesquisas telematizadas, que buscam informações em meios que combinam o computador e as telecomunicações que discorrem sobre o tema proposto. Em um segundo momento foi realizada a coleta de dados, que se deu através de instrumentos que auxiliaram no processo de busca de informações, como questionário auto-aplicado com o gestor e colaboradores de todos os departamentos da empresa. Após a aplicação do questionário, foi realizada a análise e interpretação, onde se organizou os dados de forma que possibilitou o fornecimento de respostas ao problema proposto.

A empresa alvo do estudo tem atualmente 38 colaboradores, sendo que 2 destes estavam afastados, e 3 estavam de férias e não puderam responder ao questionário. Primeiramente o questionário foi respondido pelo gerente geral da empresa, a fim de verificar se o sistema de remuneração adotado atende aos objetivos da empresa. E em seqüência, o questionário foi respondido pelos colaboradores de todos os setores da empresa. A pesquisa realizou-se nos dias 12 e 13/01/2012, nos momentos em que os colaboradores tinham um tempo vago.

\section{RESULTADOS E DISCUSSÕES}

Neste capítulo serão apresentados os dados resultantes da pesquisa realizada na empresa de materiais para construção, onde o objetivo proposto foi verificar qual estratégia de remuneração é a mais utilizada na empresa. Neste momento serão abordados os pontos mais importantes obtidos através da aplicação do questionário, assim como a discussão sobre a percepção dos colaboradores quanto à remuneração recebida, o conhecimento das estratégias dentro da empresa, e o interesse em serem remunerados de outras formas.

\subsection{Descrição do sistema de remuneração da empresa}

De acordo com os dados obtidos na pesquisa realizada com o gerente, o atual sistema de remuneração existente na empresa é a remuneração funcional e a remuneração variável, onde alguns colaboradores recebem salário e comissão, e os outros recebem somente o salário normal, e dependendo da função executada a remuneração possui valores diferentes. Na empresa não existe o pagamento de nenhum benefício aos colaboradores. 
Remuneração estratégica- estudo de caso em uma empresa do comércio varejista de materiais para construção em Tangará da Serra-MT

Andressa Ozan Oliveira

Julio Cezar de Lara

Na empresa existe a divisão de setores. Será demonstrada a estrutura organizacional e a quantidade de colaboradores em cada setor na Figura seguinte:

Figura 01: Organograma da empresa pesquisada em Janeiro de 2012.

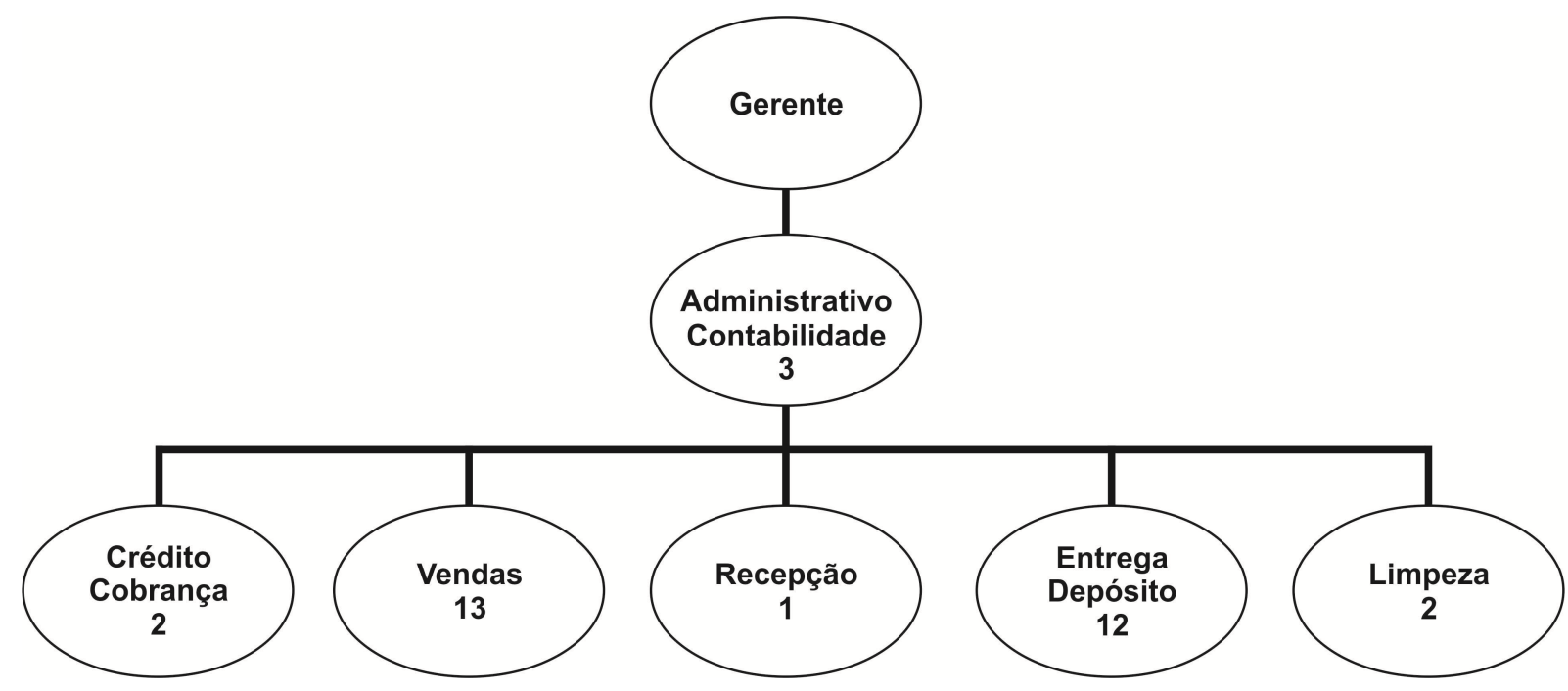

Fonte: Elaborado pelos autores

Foi questionado ao Gerente se o sistema de remuneração atende as expectativas da empresa, e a resposta foi negativa. E quando questionado sobre seu ponto de vista com relação a satisfação dos colaboradores com a remuneração obtida, a resposta foi de que estão pouco satisfeitos. Isso vai de encontro ao que diz Chiavenato (1992), onde aborda que ao salário são agregados serviços sociais e benefícios proporcionados ao seu pessoal, e que o salário e mais esses serviços e benefícios constituem a remuneração. E se o empregado não recebe os serviços e benefícios sociais, tendo que desembolsar do valor que ganha para poder usufruí-los, ele ficará insatisfeito.

\subsection{Grau de escolaridade e tempo de serviço dos colaboradores}

Foram levantados os dados quanto ao grau de instrução dos colaboradores. Sendo que $6 \%$ têm o ensino fundamental incompleto, $21 \%$ ensino fundamental completo, $18 \%$ ensino médio incompleto, $24 \%$ ensino médio completo, $28 \%$ ensino superior incompleto, e $3 \%$ ensino superior completo. Ficando constatado que uma grande parte dos colaboradores estão 
Remuneração estratégica- estudo de caso em uma empresa do comércio varejista de materiais para construção em Tangará da Serra-MT

Andressa Ozan Oliveira

Julio Cezar de Lara

cursando o ensino superior, ou seja, buscam uma melhor qualificação para seu desenvolvimento pessoal, de acordo com o demonstrado na Figura 02:

Figura 02. Grau de instrução escolar dos colaboradores da empresa em janeiro de 2012.

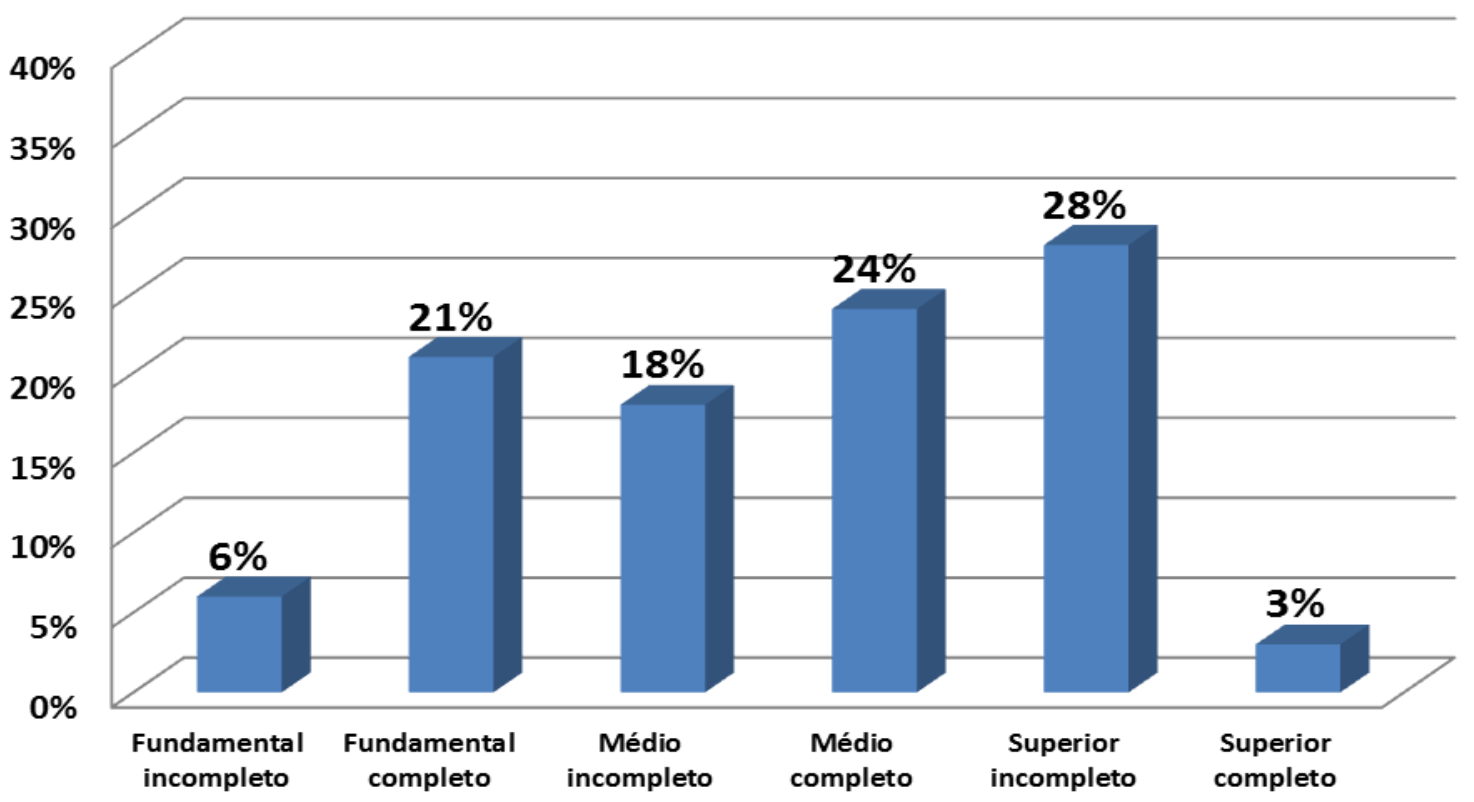

Fonte: Elaborado pelos autores

De acordo com Chiavenato (2008) em muitas organizações, os cargos são separados em três categorias predeterminadas: cargos não-qualificados, cargos qualificados e cargos especializados. Depois de determinada as categorias, é aplicado o método de escalonamento simples a cada uma delas de forma independente, sendo que cada categoria predeterminada possui seu limite inferior e limite posterior, podendo haver uma superposição entre elas. Isso faz com que os salários dos limites inferiores da categoria mais avançada se tornem menores do que os salários dos limites superiores da categoria anterior.

Em relação ao tempo de serviço dos colaboradores, constatou-se que 52\% trabalham a menos de um ano, $33 \%$ trabalham de um a três anos e somente $15 \%$ tem mais de três anos de serviço. Com isso constata-se que grande parte dos colaboradores são recém-chegados na empresa. Desta forma eles procuram alguma motivação na empresa, e o investimento em treinamentos, como veremos adiante, pode ser uma boa opção para manter os colaboradores na empresa.

4.3 Percepção dos colaboradores quanto as remunerações e grau de satisfação com a remuneração atual 
Remuneração estratégica- estudo de caso em uma empresa do comércio varejista de materiais para construção em Tangará da Serra-MT

Andressa Ozan Oliveira

Julio Cezar de Lara

Foi questionado aos colaboradores sobre quais os tipos de remuneração eles recebem atualmente na empresa. O resultado foi: $47 \%$ dos colaboradores responderam que recebem remuneração funcional, 23\% responderam que recebem remuneração variável, $6 \%$ disseram receber remuneração por competência e $24 \%$ afirmam não receber nenhum tipo de remuneração estratégica, conforme se expõe na Tabela a seguir:

Tabela 01. Percepções dos colaboradores sobre o tipo de remuneração estratégica recebida atualmente na empresa em janeiro de 2012

\begin{tabular}{cccc}
\hline $\begin{array}{c}\text { Remuneração } \\
\text { Variável }\end{array}$ & $\begin{array}{c}\text { Remuneração } \\
\text { Funcional }\end{array}$ & $\begin{array}{c}\text { Remuneração por } \\
\text { competência }\end{array}$ & $\begin{array}{c}\text { Não recebe remuneração } \\
\text { estratégica }\end{array}$ \\
\hline $23 \%$ & $47 \%$ & $6 \%$ & $24 \%$
\end{tabular}

Fonte: Elaborado pelos autores

Pode-se observar na Tabela acima que os colaboradores que responderam receber remuneração por competência estão enganados, pois de acordo com o gerente este tipo de remuneração não é atualmente utilizado pela empresa.

Ainda quando se questionou aos colaboradores sobre o conhecimento da existência de vários tipos de remuneração estratégica na empresa, 30\% disseram que existem várias formas de remuneração, $40 \%$ disseram que não existem e $30 \%$ afirmaram não saber se existem, conforme se observa na tabela abaixo:

Tabela 02. Percepções dos colaboradores sobre o conhecimento de vários tipos de remuneração estratégica recebida atualmente na empresa em janeiro de 2012

\begin{tabular}{ccc}
\hline $\begin{array}{c}\text { Existem várias formas de } \\
\text { se remunerar }\end{array}$ & $\begin{array}{c}\text { Não existem várias formas } \\
\text { de se remunerar }\end{array}$ & $\begin{array}{c}\text { Desconhecem a existência de várias } \\
\text { formas de se remunerar na empresa }\end{array}$
\end{tabular}

$\begin{array}{lll}30 \% & \mathbf{4 0 \%} & \mathbf{3 0 \%}\end{array}$

Fonte: Elaborado pelos autores

Isto comprova que grande parte dos colaboradores desconhecem os sistemas de remuneração estratégica existentes na empresa, pois ao cruzarmos os dados com as respostas obtidas sobre o tipo de remuneração recebida (Tabela 01), observamos que os colaboradores não consideram a remuneração variável e a funcional como tipos de remuneração estratégica, assim os mesmos colaboradores que dizem receber por remuneração variável, funcional e por competência (76\%) dizem não existir ou não saber se existem remuneração estratégica (70\%). 
Remuneração estratégica- estudo de caso em uma empresa do comércio varejista de materiais para construção em Tangará da Serra-MT

Andressa Ozan Oliveira

Julio Cezar de Lara

Esta percepção equivocada sobre a existência e o recebimento de remuneração estratégica pode prejudicar o desenvolvimento do trabalho e o ambiente organizacional, pois conforme Chiavenato (1992) do ponto de vista das pessoas, a recompensa proporciona um sentimento de segurança, é uma fonte de reconhecimento, e serve como um objetivo a ser atingido pela pessoa. Portanto é de extrema importância que o colaborador seja recompensado de forma a se empenhar, motivar e se manter na organização, e o que pode estar ocorrendo é que mesmo recebendo algum tipo de remuneração estratégica o sentimento de que "falta algo" é constante.

Ao questionar aos colaboradores sobre o grau de satisfação com a remuneração recebida, constatou-se que, $28 \%$ estão satisfeitos, $60 \%$ estão pouco satisfeito e $12 \%$ insatisfeito ou totalmente insatisfeito, isso demonstra a grande desmotivação dos colaboradores, sendo este um ponto negativo para a empresa conforme mostra a Figura 03.

Figura 03. Grau de satisfação sobre a remuneração atualmente recebida em janeiro de 2012.

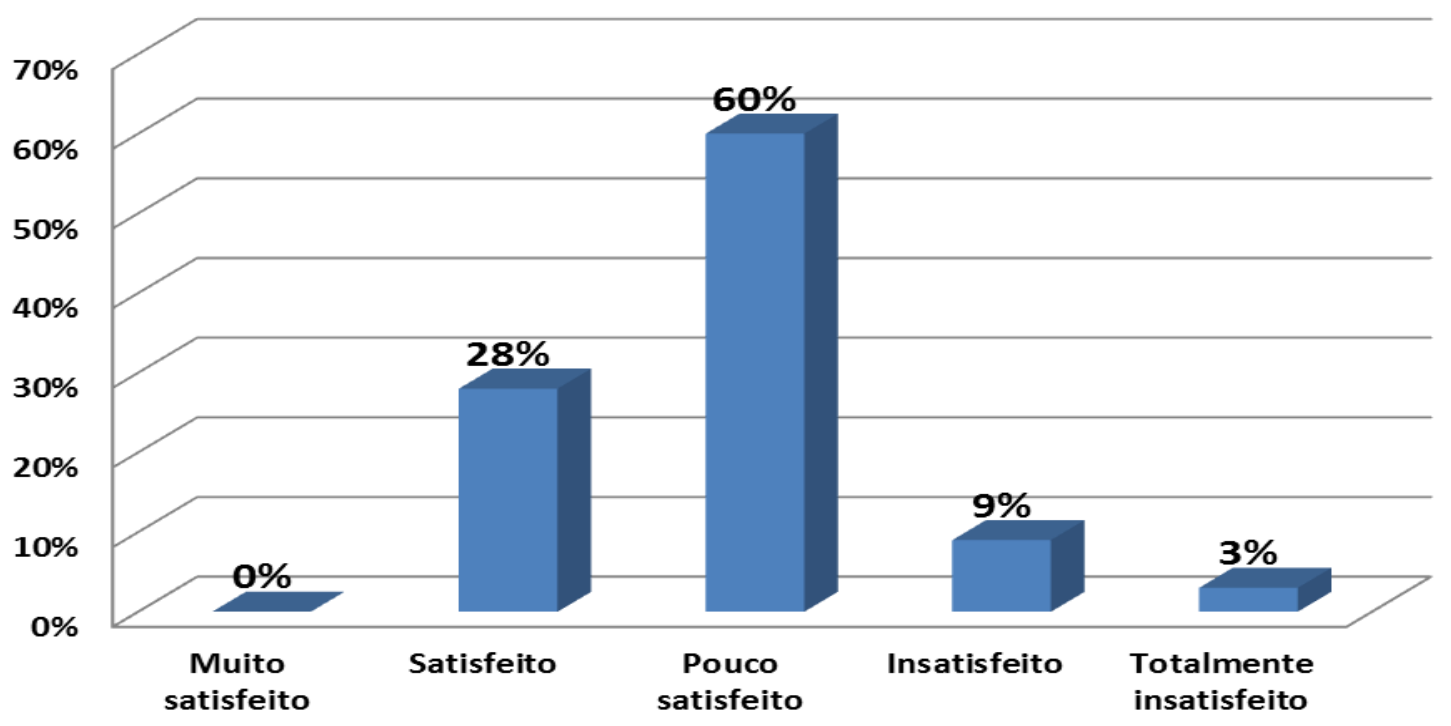

Fonte: Elaborado pelos autores

Um ponto inicial importante para motivar os colaboradores de acordo com Lacombe (2005), é identificar suas necessidades, prioridades e desejos, pois, o que motiva uns pode não ser válido para outros.

Segundo Carvalho e Serafim (1995) estar motivado significa ter uma direção, um objetivo ou meta. As pessoas têm necessidades de obter resultados para que seus trabalhos se tornem importantes, necessidades essas que fazem parte da pirâmide de Maslow, sendo elas: necessidades fisiológicas, segurança, sociais, status, estima e auto realização. 
Remuneração estratégica- estudo de caso em uma empresa do comércio varejista de materiais para construção em Tangará da Serra-MT

Andressa Ozan Oliveira

Julio Cezar de Lara

A empresa alvo da pesquisa deve focar nessas necessidades de seus colaboradores, para saber quais suas prioridades pessoais, pois conhecendo cada um de seus colaboradores poderá deixá-los mais motivados, mesmo não sendo esta uma tarefa fácil.

Com relação a treinamento proporcionado aos colaboradores, $21 \%$ responderam que receberam treinamento para a atual função e $79 \%$ responderam que não receberam nenhum tipo de treinamento.

De acordo com Lacombe (2005), treinamento não é algo feito somente uma vez para novos colaboradores, é usado sucessivamente nas organizações bem administradas. Treinamento é qualquer atividade que contribua para tornar uma pessoa apta na execução de sua função, para aumentar sua capacidade, para exercer melhor as funções, ou para exercer de forma eficiente novas atividades ou funções.

O motivo da empresa alvo da pesquisa não ter realizado treinamento com a maioria dos colaboradores, pode ser um dos motivos citados por Lacombe (2005), onde diz que uma das razões pelas quais as empresas investem menos em treinamento do que deveriam é o receio de perder o investimento, pois o empregado poderá a qualquer momento deixar empresa, e ainda poderá trabalhar para um competidor.

A maneira na qual a empresa valoriza as pessoas que dela fazem parte, reflete o grau de importância e o valor que elas têm para a organização. Isso é um ponto positivo na empresa pesquisada, pois quando questionado aos colaboradores sobre contribuir para o sucesso da empresa $97 \%$ entenderam que contribuem.

Quanto ao interesse em serem remunerados de outras formas, constatou-se que $94 \%$ gostariam de ter outras formas de remuneração, e $6 \%$ disseram que não gostariam. Das várias formas de remuneração que os colaboradores gostariam de obter, o salário indireto foi optado pela maioria dando um percentual de $59 \%$ conforme mostra a Tabela 03 .

Tabela 03. Formas de remuneração estratégica que os colaboradores gostariam de obter em janeiro 2012

\begin{tabular}{ll}
\hline Remuneração variável & $3 \%$ \\
\hline Participação nos lucros & $\mathbf{1 1 \%}$ \\
\hline Remuneração funcional & $\mathbf{3 \%}$ \\
\hline Salários indiretos & $\mathbf{5 9 \%}$ \\
\hline Remuneração por habilidade & $\mathbf{9 \%}$ \\
\hline Remuneração por competência & $\mathbf{1 2 \%}$ \\
\hline Participação acionária & $\mathbf{3 \%}$ \\
\hline
\end{tabular}

Fonte: Elaborado pelos autores 
Remuneração estratégica- estudo de caso em uma empresa do comércio varejista de materiais para construção em Tangará da Serra-MT

Andressa Ozan Oliveira

Julio Cezar de Lara

O salário indireto, que foi a opção mais escolhida pelos colaboradores dentre as formas que gostariam de serem remunerados, é conhecido como benefícios e outras vantagens. Benefícios são certas regalias e vantagens concedidas pelas organizações, a título de pagamento adicional dos salários a totalidade ou parte de seus funcionários. Constituem geralmente um pacote de benefícios e serviços que fazem parte integrante da remuneração do pessoal (Chiavenato, 2008).

\section{CONSIDERAÇÕES FINAIS}

O presente estudo se realizou com o objetivo principal de verificar na empresa de materiais para construção, qual a estratégia de remuneração é a mais utilizada.

De forma a responder ao problema proposto foram levantadas duas hipóteses, a primeira é de que a empresa não adota vários tipos de remuneração, hipótese esta que foi refutada, pois foi constatado que a empresa utiliza várias formas de remuneração, sendo elas a remuneração funcional e variável. E a segunda hipótese de que a remuneração variável é a forma mais usual na empresa, também foi refutada, já que é a remuneração funcional a maneira mais utilizada entre os colaboradores.

A metodologia utilizada contemplou de forma satisfatória para a realização da pesquisa, pois foi possível analisar de forma clara os dados e o alcance dos objetivos. Com relação ao objetivo geral, verificou-se o tipo de remuneração funcional como sendo o mais utilizado. E com relação aos objetivos específicos, foram abordados os vários tipos de remuneração utilizada pelas organizações; foi realizada a pesquisa in loco, onde se verificou o tipo de remuneração existente sendo esta a remuneração funcional; e no quesito de verificar se os colaboradores estão satisfeitos com a remuneração obtida, foi identificado que a maioria deles estão pouco satisfeitos, revelando que a prática de remuneração adotada não satisfaz os colaboradores, desta forma impactando na motivação geral dos colaboradores.

Foi percebido que o sistema atual de remuneração não atende aos objetivos e expectativas da empresa. Também foram identificadas várias formas que os colaboradores gostariam de serem remunerados, sendo optado pela maioria o salário indireto, que são incentivos que vão além do salário base e da remuneração, é normalmente conhecido como benefícios.

Através do estudo realizado, verificou-se o quanto a remuneração estratégica influencia no desempenho da organização e na motivação e incentivo de seus colaboradores, e 
Remuneração estratégica- estudo de caso em uma empresa do comércio varejista de materiais para construção em Tangará da Serra-MT

Andressa Ozan Oliveira

Julio Cezar de Lara

o quanto as empresas podem se tornar altamente competitiva com relação às outras. Por isso, é de fundamental importância que a empresa, alvo da pesquisa, encontre uma forma de atrair e reter seus colaboradores, utilizando a remuneração que mais adéqua ao seu perfil e dos seus colaboradores, e também os incentivem para que se tornem cada vez mais qualificados.

Pode se observar que a abordagem sobre remuneração estratégica é um assunto novo para a empresa, ou seja, não é algo que eles têm total conhecimento, e pelo fato de não dominarem a dimensão do tema da pesquisa, pode haver alguma distorção nos resultados apresentados.

O presente trabalho também tem a função de contribuir para a empresa alvo da pesquisa. Foram identificados pontos positivos e negativos existentes, mas sempre com o intuito de cooperar para uma futura melhoria.

Percebe-se que é viável a realização de uma reavaliação do sistema de remuneração adotado, com intuito de verificar a forma mais adequada a necessidade dos colaboradores e da empresa, pois conforme a pesquisa realizada os colaboradores não se encontram satisfeitos e a empresa pode não estar atingindo os objetivos organizacionais pretendidos.

É importante que a empresa encontre formas de reter seus colaboradores, pois como a pesquisa demonstrou, os colaboradores têm a expectativa de maiores salários e a maioria deles gostariam de receber salários indiretos, sendo esta uma excelente opção de remuneração a ser inserida na empresa.

Não pretendemos esgotar o tema nesse estudo, mas sim de abrir a discussão sobre a temática proposta, e por se tratar de um tema pouco explorado e de suma importância as organizações, é interessante que sejam desenvolvidos novos trabalhos na área de estudo abordada, dando ênfase a outros ramos de atividades, para verificar como está a relação das empresas com a remuneração estratégica. 
Remuneração estratégica- estudo de caso em uma empresa do comércio varejista de materiais para construção em Tangará da Serra-MT

Andressa Ozan Oliveira

Julio Cezar de Lara

\section{REFERÊNCIAS BIBLIOGRÁFICAS}

CARDOSO, Luiz Roberto. Avaliando sistemas de remuneração baseados em habilidades e competência: A visão do profissional de gestão de pessoas- 2006, Disponível em: $<200.169 .97 .104 /$ seer/index.php/RBGN/article/viewFile/57/51> Acesso em 05 de Outubro de 2011.

CARVALHO, Antônio Vieira de; SERAFIM, Oziléia Clen Gomes. Administração de recursos humanos. São Paulo: Pioneira, 1995.

CHIAVENATO, Idalberto. Gerenciando pessoas: $O$ passo decisivo para a administração participativa. São Paulo: Makron Books, 1992.

Gerenciando com as pessoas: transformando o executivo em um excelente gestor de pessoas. Rio de Janeiro: Elsevier, 2005.

Gestão de pessoas. Rio de Janeiro: Elsevier, 2008.

DANTAS, Sergio Silva. Análise do comprometimento dos funcionários: Um estudo em uma empresa de call Center- 2005 Disponível em:

<http://www.ead.fea.usp.br/semead/8semead/resultado/an_resumo.asp?cod_trabalho=125> Acesso em: 09 de Outubro de 2011.

ESTIVALETE, V. F. B; NAKAYAMA, M. K; BINOTTO, E. A gestão estratégica da remuneração- estudo de caso em uma cooperativa.- 2009. Disponível em:

<http://www.fearp.usp.br/egna/resumos/Estivalete.pdf> Acesso em: 10 se Setembro de 2011. FERRÃO, Eliene Maria Gava. Gestão estratégica de sistemas de recompensa de pessoas. 1999. Disponível em:

<http://www.univen.edu.br/revista/n013/GEST\%C3O\%20ESTRAT\%C9GICA\%20DE\%20SI STEMAS\%20DE\%20RECOMPENSA\%20DE\%20PESSOAS.pdf> Acesso em: 15 de Setembro de 2011.

GIL, Antonio Carlos. Gestão de Pessoas: Enfoque nos papéis profissionais. São Paulo: Atlas, 2001.

GONSALEZ, Carlos et al. Estudos sobre técnicas e fatores motivacionais nas empresas.

Revista Científica Famec, V. 3, n. 1, São José dos Pinhais, Junho de 2007.

IUDÍCIBUS, Sérgio de; MARION, José Carlos. Contabilidade Comercial. São Paulo: Atlas, 2004.

LACOMBE, Francisco José Masset. Recursos humanos: princípios e tendências. São Paulo: Saraiva, 2005.

LIMA,G.; NEU, T. D.; CACENOTE, A. M. Remuneração estratégica: Uma nova visão empresarial-2010, Disponível em:

http://www.fema.com.br/revistas/eletronica/publicacoes/remuneracao_estrategica_uma_nova_ visao_empresarial.pdf> Acesso em: 10 de Setembro de 2011.

MALANOVICZ, Aline Vieira; WEBER, Letícia. Práticas de remuneração como estratégica para reter talentos: Um estudo de caso em uma empresa de serviços. In: $1^{\circ}$ Simpósio Brasileiro de Ciência de serviços, 2010, Brasília. Anais... Brasilia: Reser, 2010.

MARRAS, Jean Pierre. Administração da remuneração. São Paulo: Thomson Learning, 2002.

NASCIMENTO, Luiz Paulo do. Administração de cargos e salários. São Paulo: Pioneira Thomson Learning, 2001.

OLIVEIRA, Lucia Maria Barbosa de. Estratégias e Práticas de Remuneração Utilizadas pelas Empresas Brasileiras. Revista O\&M, Salvador, V. 8, n. 21, Agosto de 2001.

RAMOS, Bruno Schmidt. FERREIRA, Camila Lopes. O aumento da produtividade através da valorização dos colaboradores uma estratégia para a conquista de mercado. Revista de engenharia e tecnologia, Paraná, V.2, n. 2, Agosto de 2010. 
Remuneração estratégica- estudo de caso em uma empresa do comércio varejista de materiais para construção em Tangará da Serra-MT

Andressa Ozan Oliveira Julio Cezar de Lara

RODRIGUES, M. V. et al. Remuneração estratégica: um pilar para o desenvolvimento das organizações. In: XXVIII Encontro Nacional de engenharia e produção, 2008, Rio de Janeiro. Anais. Rio de Janeiro: Abepro, 2008.

SOCHODOLAK, Cleberson Rodrigo; MELO JUNIOR, Aroldo Messias de. O plano de cargo e salários como ferramenta de gestão. Revista Eletrônica Lato Sensu- Ciências sociais aplicada, Paraná, v.3, n. 1, Março de 2008.

VELOSO, C. C, et al. Remuneração estratégica: Uma dinâmica da atividade profissional no cenário empresarial- 2008. Disponível em:

$<$ http://www.webartigos.com/artigos/remuneracao-estrategica-uma-dinamica-da-atividadeprofissional-no-cenario-empresarial/10647/> Acesso em: 05 de Outubro de 2011.

VERGARA, Sylvia Constant. Projetos e relatórios de pesquisa em administração. São Paulo: Atlas, 2009.

VILAS BOAS, Ana Alice. BATISTA, Luciene Gouveia. As metodologias de remuneração variável adotada nas empresas brasileiras e sua influencia na mudança organizacional.

Revista eletrônica de ciência administrativa, Campo Largo, v. 3 n. 1, Maio de 2004. WOOD JUNIOR, Thomaz. PICARELLI FILHO, Vicente. Remuneração Estratégica: A nova vantagem competitiva. São Paulo: Atlas, 2004.

YIN, Robert Key. Estudo de caso- planejamento e métodos. Porto Alegre: Editora Bookman, 2001. 